\title{
Efficacy and Safety of Radiofrequency Ablation for the Treatment of Autonomously Functioning Thyroid Nodules: A Long-Term Prospective Study
}

\author{
Dang Luu Vu (D' \\ Minh Thong Pham' \\ Van Bang Nguyen (D) ${ }^{2}$ \\ Thi My Le (iD) 3 \\ 'Bach Mai Radiology Center, Bach Mai \\ Hospital, Hanoi, Vietnam; ${ }^{2}$ Center of \\ Endocrinology and Diabetes, Family \\ Hospital, Da Nang, Vietnam; ${ }^{3}$ Radiology \\ Department, Vinmec Times City \\ International Hospital, Hanoi, Vietnam
}

Correspondence: Thi My Le Radiology Department, Vinmec Times City International Hospital, Hanoi, Vietnam $\mathrm{Tel}+84979600233$

Email v.mylt8@vinmec.com
Objective: This study aims to evaluate the efficacy and safety of RFA in the AFTN treatment after 2 years of follow-up and to find the factors related to treatment responses through TSH level and VRR.

Materials and Methods: This long-term prospective study was conducted from September 2017 to April 2021 on 17 AFTNs treated with RFA. Clinical evaluations, thyroid function tests, thyroid scintigraphy, and ultrasonography examinations were performed at 1 month, 3 months, 6 months, and 24 months after ablation. The primary endpoint was the success rate of RFA in restoring the euthyroidism stage after 24 months of follow-ups; secondary outcomes were VRR and improvements of US parameters, clinical examinations, and complications. The Spearman rank correlation test was used to determine related factors with treatment response variables.

Results: At the 24 months after the procedure, symptom score, cosmetic score, vascularity grade, and nodule volume significantly decreased. The VRR reduced approximately $42.77 \%, 63.13 \%$, $78.3 \%$, and $95.65 \%$ after 1 month, 3 months, 6 months, and 24 months follow-up. All 17 patients were restored euthyroid state without taking ATDs. No major complications were collected. The last TSH level was significantly correlated with the age of patients (Spearman rho $=-0.637, p=0.008$ ). The VRR was significantly correlated with age of patients (Spearman rho $=0.566, p=0.018$ ) and initial TSH (Spearman rho $=0.485, \mathrm{p}=0.048)$.

Conclusion: RFA was demonstrated as a safe and effective option for AFTN treatment in long-term follow-up. It can be used as an alternative treatment with encouraging results.

Keywords: radiofrequency ablation, thyroid nodules, autonomously functioning thyroid nodule

\section{Introduction}

The autonomously functioning thyroid nodule (AFTN), the prevalence from $0.9 \%$ up to $9 \%$ of all thyroid nodules, is a predominantly benign neoplasm presenting as a solitary hyperfunctioning nodule, inside healthy thyroid parenchyma. ${ }^{1,2}$ Because of the strong concentration of Iodine-131 or $99 \mathrm{mTc}$ used as a radiotracer (dose, $50 \mu \mathrm{Ci}$ of Iodine-131) by thyroid scintigraphy, it can be seen as a "hot spot", different from the surrounding thyroid tissue. AFTNs can cause functional abnormalities, from euthyroidism to subclinical hyperthyroidism (pre-toxic nodule) and overt hyperthyroidism (toxic nodule). ${ }^{3}$ Thus, after confirming benign thyroid nodule(s), treatment decisions usually depend on the presence of nodule-related clinical hyperthyroidism symptoms, compressive and/or cosmetic issues. ${ }^{4-8}$ 
In worldwide and Vietnam, anti-thyroid drugs (ATDs), thyroid lobectomy, or radioiodine (RI) treatment are preferred for treating AFTNs but both have limitations. ATDs decrease thyroid hormone production in the short term and are not effective in the long term. ${ }^{9}$ The disadvantage of surgery is a high risk of general anesthesia, secondary hypothyroidism, and ugly scar. Using RI treatment often requires a second treatment session because of the higher risk of failure after the first session by large nodules. Also, young women of childbearing age and patients who can stand living with hypothyroidism may not be suitable with this therapy. In addition, another disadvantage is radiation exposure. ${ }^{10-13}$

In the last few years, radiofrequency ablation (RFA) has been rising from a new treatment way of symptomatic thyroid nodule(s) as a minimally invasive procedure. It has been used for the treatment of not only non-functional benign thyroid nodules but also AFTNs according to recent guidelines. ${ }^{6,14,15}$ However, the efficacy of RFA on AFTNs is highly fluctuating in the rate of thyroid function normalization (24-82\%) and in the volume reduction rate $(\mathrm{VRR})>50 \%{ }^{16-22}$

In Vietnam, RFA has been applied for benign thyroid nodules since 2016. Thus, a few studies about the safety and efficacy of RFA for benign thyroid nodules were available and no study demonstrated its efficacy on AFTNs. $^{23,24}$ Therefore, our study aims to evaluate the efficacy and safety of RFA in the AFTN treatment after 2 years of follow-up and to find the factors related to treatment responses through TSH level and VRR.

\section{Materials and Methods}

\section{Study Design and Patient's Selection}

This study was conducted in accordance with the Declaration of Helsinki. The Ethics Committee of the Institutional Review Board of Bach Mai hospital and Hanoi Medical University, Hanoi, Vietnam approved this prospective study (number: 62720501) and written informed consent for RFA procedures for AFTN was signed by all patients.

Inclusion criteria included: (1) presence of an AFTN (as low serum TSH level and/or increased serum total triiodothyronine/free thyroxine (T3/FT4) levels and thyroid scintigraphy); (2) benign thyroid nodule(s) was confirmed by the sonographic result and two different times of US-guided fineneedle aspiration cytology (US-FNAc) ${ }^{25}$ (2) restore euthyroid stage before RFA procedures; (3) refusal or had contraindications to do surgery or RI. This study was excluded if any of the following criteria were met: (1) high risk of malignant features of AFTNs during sonographic examination (according to ACR-TIRADS 4 to 5) or FNA cytology (according to Bethesda Class III to VI); (3) current severity of thyrotoxicosis or high risk of thyroid storm; (4) pregnancy; and (5) patients lost to follow-up.

From September 2017 to April 2021, 17 patients using RFA treatment were enrolled in this study.

\section{Measurement and Assessment Pre-Ablation Evaluations}

Before the procedure, clinical examination, US, thyroid scintigraphy using Iodine-131 or 99mTc, 2 times of US-guided FNAc, and the laboratory studies were done. At the initial time, the compressive symptom was evaluated by asking patients via a visual analog scale (from 0 to 10), and a cosmetic score was followed as clinical examination: 1 , no palpable mass; 2, a palpable mass but no cosmetic problem; 3 , cosmetic problem on swallowing only; 4 , readily detected cosmetic problem. ${ }^{26}$ Only one radiologist with more than 5 years of US experience performed real-time ultrasonography (Voluson E8 Ultrasound System, GE Healthcare, USA) with an 8 to $12 \mathrm{MHz}$ linear probe. Nodule(s) was assessed the position (left/isthmus/right lobe), size, solid/mixed echoic/cystic proportions, echogenicity, vascularity grade of thyroid nodules (according to a 5-point scale where no signal in the tumor, considering as grade 0 ; a few spotty signals in the tumor, considering as grade 1 ; signals in $<25 \%$ of the tumor, considering as grade 2 ; signals from $25 \%$ to $50 \%$ of the tumor, considering as grade 3 ; and signals in $>50 \%$ of the tumor, considering as grade 4$)^{17}$ and the volume of the AFTN was calculated using the formula: $\mathrm{V}=\pi \mathrm{abc} / 6$ - where $\mathrm{a}, \mathrm{b}, \mathrm{c}$ are the 3 diameters, $\mathrm{V}$ is volume. Ultrasound-guided FNA was done by a licensed radiologist (TM Le) and pathologist with more than 5 years of experience. Thyroid function (thyroidstimulating hormone (TSH), free thyroxine (FT4) level, and triiodothyronine (T3)) were obtained. The normal ranges of serum TSH, FT4, and T3 are 0.27-4.42 microIU/mL, 12-22 $\mathrm{pmol} / \mathrm{L}$, and $1.3-3.1 \mathrm{nmol} / \mathrm{l}$, respectively. Before the RFA procedure, we explained this therapy carefully to each patient.

\section{Radiofrequency Ablation Procedure}

The same radiologist (TM Le) performed all the RFA procedures at the outpatient department of the Radiology Center, Bach Mai Hospital, Hanoi, Vietnam. After local anesthesia by injecting $2 \%$ lidocaine at the needle-puncture site and thyroid capsule with a supine position and mild neck extension, an 18 gauge internally 
cooled electrodes $(5 \mathrm{~mm}, 7 \mathrm{~mm}$, or $10 \mathrm{~mm}$ in active tips $)$ connected to a radiofrequency generator (VIVA RF Generator, STARmed Co., Ltd., Korea) was used to puncture into the nodule under US guidance. Theoretically, AFTN was ablated by 2 basic techniques: the transisthmic approach and the moving-shot technique. To protect important structures, hydro-dissection by slowly injecting 5\% dextrose was used in a few cases. AFTN was ablated completely when the transient hyperechoic zone was presented. ${ }^{25-27}$ In the case of the predominantly solid nodule(s), the nodule was ablated after fluid aspiration. Patients were evaluated for complications and discharged after 60 minutes of follow-up without complications.

\section{Follow-Up of the Patients}

Patients were followed up at 1 month, 3 months, 06 months, and 24 months after the treatment session. US evaluation, thyroid function tests (TSH, FT4, and T3), thyroid scintigraphy (Iodine-131 or $99 \mathrm{mTc}$ ), symptom score, and cosmetic score were evaluated at every visit time. On US re-examination, we evaluated changes in the nodular diameters, volume, and vascularity grade. VRR of the treated nodule was calculated based on the formula:

$\operatorname{VRR}(\%)=\frac{\text { (Baseline volume-posttreatment volume) }}{\text { Baseline volume }} \times 100 \%$

In thyroid scintigraphy evaluation, three categories of thyroid nodules were determined: hot nodule, considered as type 1; nodule takes up Iodine-131 or $99 \mathrm{mTc}$ similar to extra-nodular thyroid tissue, considered as type 2 ; and cold nodule or invisible status, considered as type $3 .{ }^{17}$ If the nodule's portion with vascularity was detected on color Doppler ultrasound images and VRR is too small, additional treatment sessions should be considered because of the potential for regrowth. Also, specific complaints were recorded in the follow-up period.

\section{Efficacy Outcome}

Our primary endpoint was to evaluate the success rate of RFA in restoring the euthyroidism stage (clinical symptoms, serum TSH concentration, and scintigraphy evaluation) 24 months after the procedure. Secondary endpoints include VRR and improvements in vascularity grade on US, symptoms, and cosmetic scores.

\section{Safety Outcome}

Complications of RFA were followed as the recommendations of the international working group on image-guided tumor ablation. ${ }^{28}$ Substantial morbidity and disability that increases the level of care, hospital admission, hemorrhage need a blood transfusion, and permanent voice change were considered major complications. Pain, transient voice change, vomiting, and skin burns were identified as minor complications.

\section{Patient Characteristics and Other Factors}

Patient information included age (continuous variable), sex (categorical variable: male and female), the severity of thyrotoxicosis symptoms (categorical variable: pretoxic nodule (subclinical hyperthyroidism), and toxic nodule (overt hyperthyroidism)). Treatment characteristics included ablation time (continuous variable: minute), RF power (continuous variable: Walt), and the number of RFA sessions (continuous variable).

\section{Statistical Analysis}

All statistical analyses were done using SPSS version 20.0 for Windows. Continuous variables were shown as means $\pm \mathrm{SD}$; categorical variables were calculated as frequencies or percentages. The number of RFA's complications and their percentage were calculated as the safety outcome. To evaluate the RFA efficacy, our purpose is to calculate the VRR, symptoms, and cosmetic scores during the followup period ( 1 month, 3 months, 6 months, and 24 months post-ablation) and to calculate the rate of patients who restored euthyroidism through serum TSH concentration in every follow-up period. To compare the changes in symptom score, cosmetic score, thyroid function tests (TSH, FT4, T3), nodule volume, largest diameter, VRR, and vascularity grade from the initial time to 1 month, 3 months, 6 months, and 24 months after the procedure, a general linear model with multiple repeated measurements was performed.

The relationship of patient's characteristics (age), nodular characteristics (position, initial volume, initial largest diameter, TSH, solid composition, cosmetic score, symptom score, and vascularity grade), and procedure's parameters (number of treatment session, RF power, and ablation time) with treatment response variables (TSH level and VRR) was calculated using the Spearman rank correlation test. Statistical significance was defined as p-value $<0.05$.

\section{Results}

From September 2017 to April 2021, 17 patients with 17 AFTNs were enrolled in this study. 


\section{Baseline Characteristics of the Patients and Nodules}

The baseline demographic information of the patients and nodules are shown in Table 1 . In this study, the patients were 15 women and 2 men, whose mean age was $46.47 \pm$ 13.11 years (range 28-66). The mean symptom score, cosmetic score, and vascularity grade were 3.47, 3.59, and 3.12, respectively. At the pre-ablation time, the mean largest diameter AFTN was $38.59 \pm 9.70 \mathrm{~mm}$ (range 22.055.0 ) with a mean volume of $13.07 \pm 8.45 \mathrm{~mL}$ (range 2.235.5). Among the 17 treated thyroid nodules, there were 10 solid (58.8\%) and $7 \mathrm{mix}$ solid nodules $(41.2 \%)$. Thyroid functions include mean concentrations of $\mathrm{TSH}$, FT4, and T3 were $0.10 \mathrm{mUI} / \mathrm{mL}, 16.31 \mathrm{ng} / \mathrm{dL}$, and 2.59

Table I Baseline Characteristics of the Patients and Nodules

\begin{tabular}{|c|c|}
\hline Characteristics & $\begin{array}{l}\text { Summary Statistics } \\
(\mathbf{N}=\mid 7)\end{array}$ \\
\hline Number of patients & 17 \\
\hline Number of nodules & 17 \\
\hline Age (years) $[($ mean $\pm \mathrm{SD})$ (range) $]$ & $46.47 \pm 13.11(28-66)$ \\
\hline Female $[\mathrm{n}(\%)]$ & $15(88.2)$ \\
\hline \multicolumn{2}{|l|}{ Nodule position [n (\%)] } \\
\hline Left & $9(52)$. \\
\hline Isthmus & I (5.9) \\
\hline Right & $7(4 I .2)$ \\
\hline Mean nodule volume $(\mathrm{mL})[($ mean $\pm \mathrm{SD})$ (range) $]$ & $13.07 \pm 8.45(2.2-35.5)$ \\
\hline $\begin{array}{l}\text { Mean largest nodule diameter }(\mathrm{mm})[(\text { mean } \pm \mathrm{SD}) \\
\text { (range) }]\end{array}$ & $38.59 \pm 9.7(22.0-55.0)$ \\
\hline \multicolumn{2}{|l|}{ Internal nodule component [n (\%)] } \\
\hline Solid & $10(58.8)$ \\
\hline Mix solid & $7(4 I .2)$ \\
\hline $\mathrm{FT} 4(\mathrm{ng} / \mathrm{dL})[($ mean $\pm \mathrm{SD})$ (range) $]$ & $16.31 \pm 5.79(5.86-28.00)$ \\
\hline $\mathrm{T} 3(\mathrm{nmol} / \mathrm{L})[($ mean $\pm \mathrm{SD})$ (range) $]$ & $2.59 \pm 1.19(1.21-5.70)$ \\
\hline $\mathrm{TSH}(\mathrm{mlU} / \mathrm{mL})[($ mean $\pm \mathrm{SD})$ (range) $]$ & $0.10 \pm 0.18(0.005-0.69)$ \\
\hline Toxic [n (\%)] & $7(4 \mid .2)$ \\
\hline Pretoxic [n (\%)] & $10(58.8)$ \\
\hline Vascularity grade $[($ mean $\pm S D)$ (range)] & $3.12 \pm 0.78(2-4)$ \\
\hline Cosmetic score $[($ mean $\pm \mathrm{SD})($ range $)]$ & $3.59 \pm 0.79(1-4)$ \\
\hline Symptom score $[($ mean \pm SD) $($ range $)]$ & $3.47 \pm 1.91(0-6)$ \\
\hline
\end{tabular}

Abbreviations: SD, standard deviation; FT4, free thyroxine; TSH, thyroidstimulating hormone; T3, triiodothyronine. $\mathrm{nmol} / 1$, respectively. Seven subjects had respectively toxic and others had pre-toxic nodules.

\section{Characteristics of RFA Treatment and Complications}

Table 2 shows our treatment characteristics and complications. $88.2 \%$ of patients had been treated by only one RFA session and others (11.8\%) were used 2 RFA sessions. The ablation time and RF power ranged from 10 to 40 minutes (mean $\pm \mathrm{SD}, 23.35 \pm 8.81$ minutes) and from 30 to 40 $\mathrm{W}$ (mean $\pm \mathrm{SD}, 33.82 \pm 4.85 \mathrm{~W}$ ), respectively.

During RFA, slight pain and a heat sensation in the electrode puncture site that radiated to the chest and shoulder were reported in most patients. No major complications were collected.

\section{The Treatment Efficacy and Its Related Factors}

The treatment clinical outcomes and US evaluations are summarized in Figure 1A-F. At the 24 months after the procedure, symptom score, cosmetic score, and vascularity grade significantly decreased from 3.47 to 0.06 (symptom score), from 3.59 to 1.19 (cosmetic score), and from 3.12 to 0.12 (vascularity grade) with $\mathrm{p}<0.0001$. A significant decline of the mean largest diameter was observed from $38.59 \pm 9.69 \mathrm{~mm}$ at an initial time, $31.41 \pm 7.69 \mathrm{~mm}$ at 1-month post-ablation, $27.0 \pm$ $8.4 \mathrm{~mm}$ at 3 months, $22.23 \pm 6.35 \mathrm{~mm}$ at 6 months, and 12.47 $\pm 5.01 \mathrm{~mm}$ with $\mathrm{p}<0.0001$. The nodule volume $(\mathrm{p}<0.0001)$ was seen rapid decrease from an initial time $(13.07 \pm 8.44 \mathrm{~mL})$ to 1 month $(7.3 \pm 4.19 \mathrm{~mL}), 3$ months $(4.88 \pm 3.34 \mathrm{~mL}), 6$ months $(2.75 \pm 1.82 \mathrm{~mL})$, and 24 months $(0.498 \pm 0.45 \mathrm{~mL})$. This represents approximately $42.77 \%, 63.13 \%, 78.3 \%$, and 95.65\% of the VRR after 1 month, 3 months, 6 months, and 24 months follow-ups.

Table 2 Characteristics of Nodule Treatment

\begin{tabular}{|c|l|}
\hline Characteristics & $\begin{array}{l}\text { Summary Statistics } \\
\mathbf{( N = ~ 1 7 )}\end{array}$ \\
\hline RFA session [n (\%)] & $15(88.2)$ \\
\hline I time & $2(11.8)$ \\
\hline 2 times & $33.82 \pm 4.85(30-40)$ \\
\hline RF power (Walt) [(mean \pm SD) (range)] & $23.35 \pm 8.81(10-40)$ \\
\hline $\begin{array}{l}\text { Ablation time (minute) [(mean } \pm \text { SD) } \\
\text { (range)] }\end{array}$ & \\
\hline
\end{tabular}

Abbreviations: SD, standard deviation; RFA, radiofrequency ablation. 

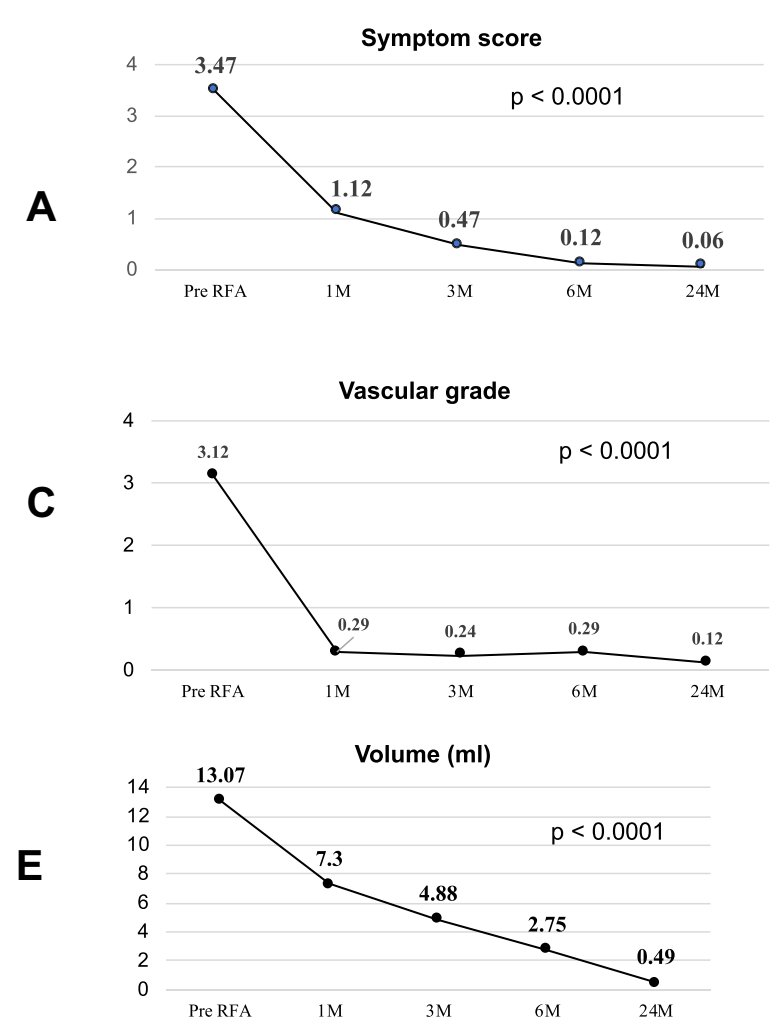
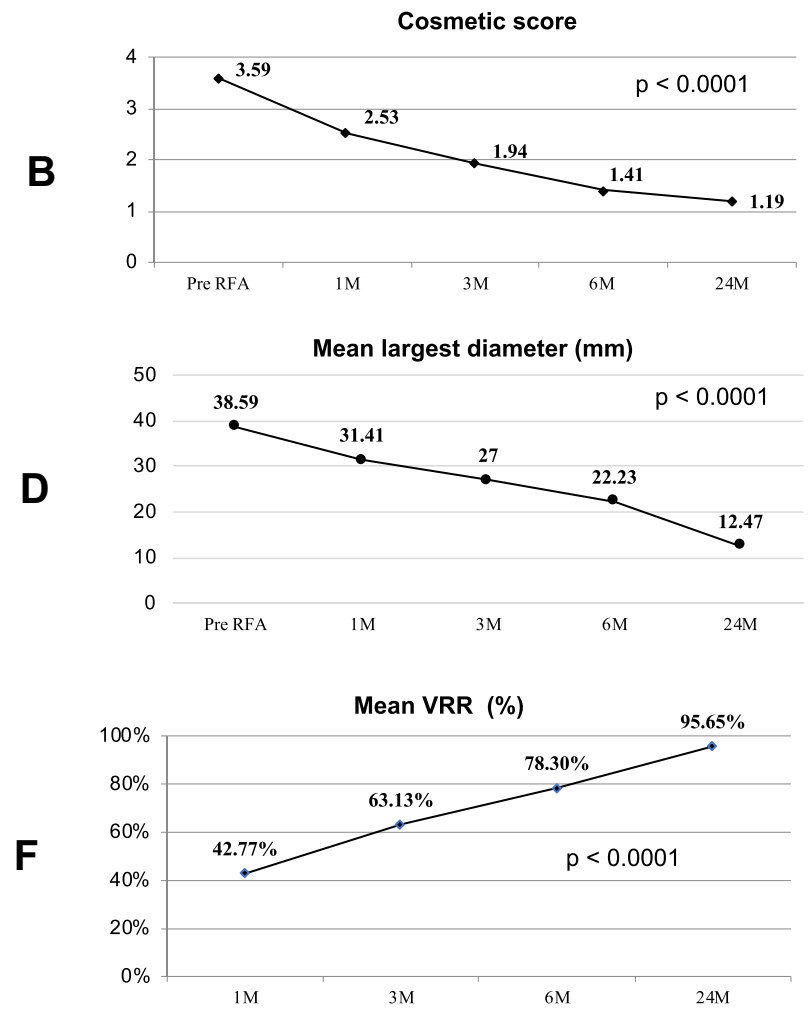

Figure I The treatment clinical outcomes and ultrasound evaluations. The symptom score (A), cosmetic score (B), and vascularity grade (C) significantly decreased. The mean largest diameter (D) and the nodule volume (E) were seen rapid decrease from an initial time to 24 months. This represents increase of the VRR (F) after I month, 3 months, 6 months, and 24 months follow-ups.

Figure $2 \mathrm{~A}-\mathrm{C}$ shows laboratory results in every period follow-up. A significant improvement of mean T3, FT4, and TSH was observed at the last follow-up. Mean TSH concentration increased from $0.101 \mathrm{mUI} / \mathrm{mL}$ to $1.69 \mathrm{mUI} / \mathrm{mL}$. This represents the reduction of mean $\mathrm{T} 3$ post-ablation from 2.59 $\mathrm{nmol} / \mathrm{l}$ at the initial time to $2.05 \mathrm{nmol} / \mathrm{l}$ at 24 months followup $(\mathrm{p}<0.05)$. Especially, mean FT4 significantly decreased from initial to 3 months post-ablation before slightly increased at 6 months and 24 months post-ablation. All 17 patients were restored euthyroid state that was evaluated by serum TSH concentration and thyroid scintigraphy at the last time follow-up without taking ATDs.

\section{Factors Affecting the Responses of Serum TSH and VRR}

The last TSH level was significantly correlated with the age of patients (Spearman rho $=-0.637, p=0.008$ ). In addition, the VRR was significantly correlated with age of patients (Spearman rho $=0.566, \mathrm{p}=0.018$ ) and initial TSH (Spearman rho $=0.485, \mathrm{p}=0.048)$.

Other factors had no significant correlation with serum TSH and VRR in our study.

\section{Representative Typical Cases}

A 54-year-old woman complained about a left neck tumor, dysphagia, and hyperthyroidism symptoms. Thyroid ultrasonography showed a right solid nodule with the volume of approximately $6.7 \mathrm{~mL}$ (Figure 3A). Cosmetic score, symptom score, and vascularity grade (Figure 3B) were 4, 5, and 3, respectively. The pre-ablation sonographic images, thyroid scintigraphy (Figure 3C), thyroid function tests, and 2 times of US-FNAc show a benign right AFTN.

We applied RFA therapy by using 18 gauge internally cooled electrodes ( $7 \mathrm{~mm}$ in active tips). The trans-isthmic approach and the moving-shot technique were used in our procedure.

After 24 months of follow-up, the VRR was relatively $98 \%$ and vascularity grade 1 (Figure $3 \mathrm{D}$ and $\mathrm{E}$ ). The cosmetic score and symptom score were an improvement. In thyroid scintigraphy, the hot nodule was not detected (Figure 3F).

\section{Discussion}

Benign thyroid nodule(s) is not a rare disease. ${ }^{29}$ In contrast, AFTN's prevalence is scarce in clinical practice. ${ }^{1,2}$ It can cause not only hyperthyroidism symptoms but also 
TSH (mU/mL)

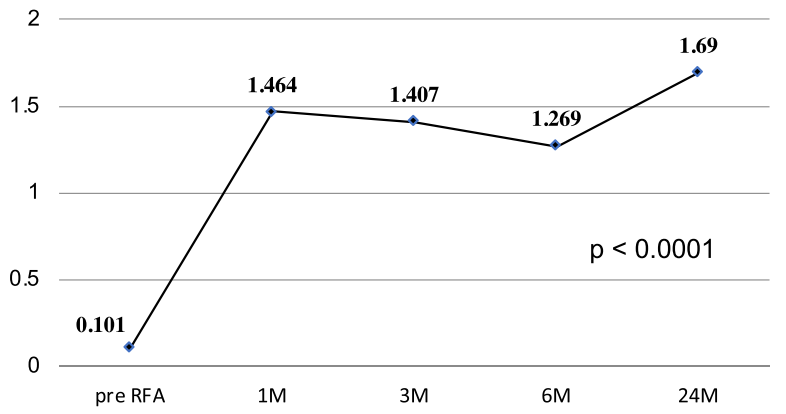

A

T3 (nmol/L)

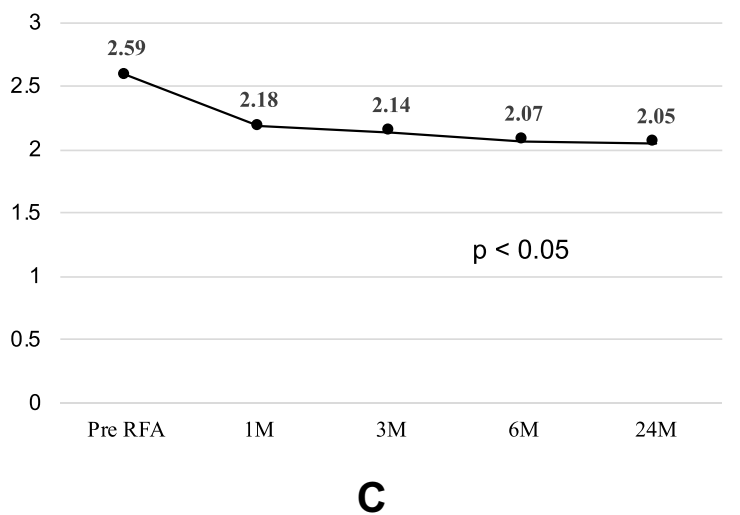

FT4 (pmol/L)

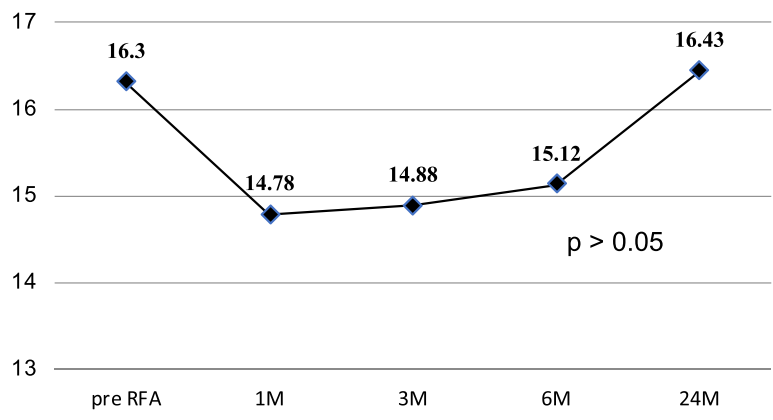

B

Figure 2 Laboratory results in every follow-up period from initial time to 24 months post-ablation. (A-C) A significant improvement of mean T3, FT4, and TSH was observed at the last follow-up.
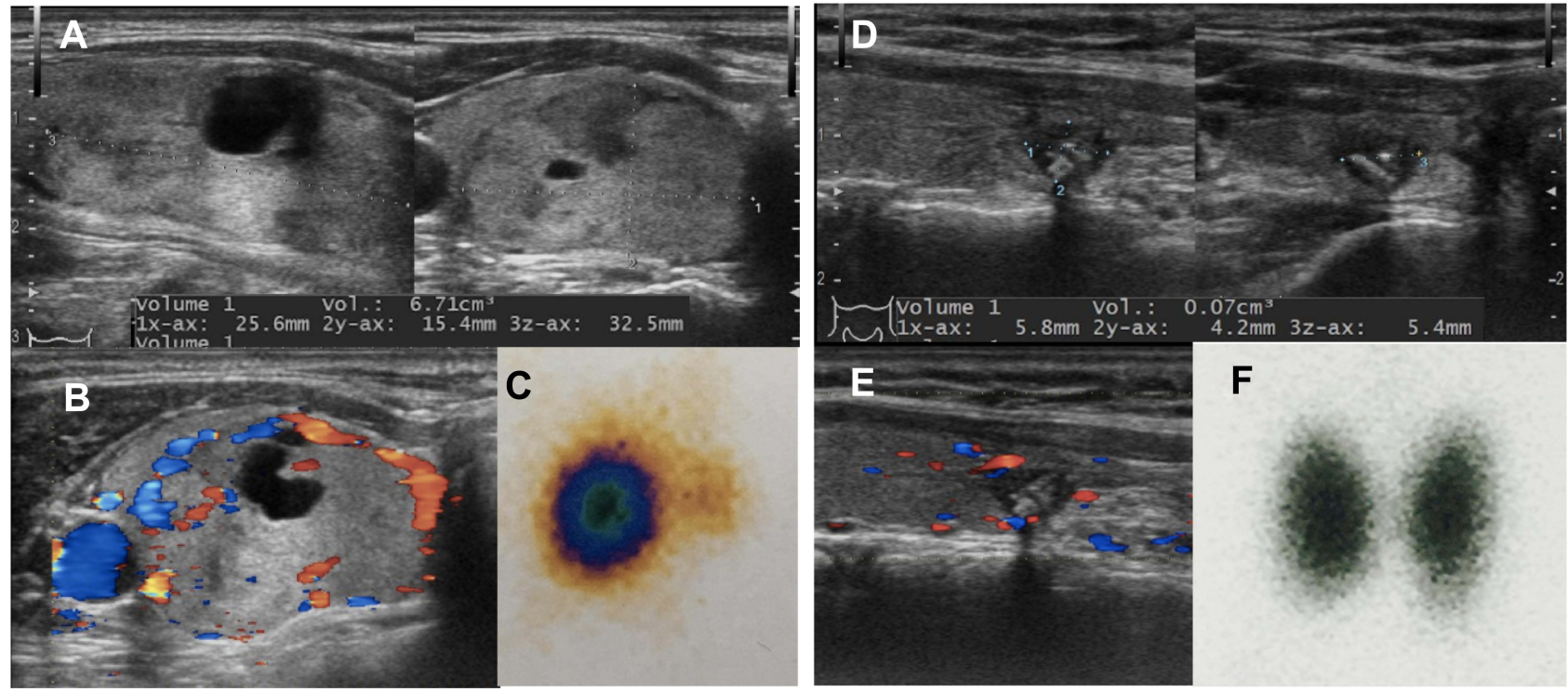

Figure 3 A 54-year-old woman presented with right neck bulging and hyperthyroidism symptoms who underwent radiofrequency ablation for AFTN treatment. (A) Initial volume of large thyroid nodule: $15 \times 26 \times 33 \mathrm{~mm}, V \sim 6.7 \mathrm{~mL}$. (B) Vascularity grade 2 in US. (C) At initial time, hot nodule presented in thyroid scintigraphy. (D) After 24 months ablation, VRR was $98 \%$, (E) Vascularity grade 0 . (F) Hot nodule was not totally detected in thyroid scintigraphy. 
compressive and/or cosmetic problems. Thus, AFTN's treatment is required. Anti-thyroid drugs (ATDs), thyroid lobectomy, or radioiodine (RI) are the most conventional way for treatment but both of them have limitations. ${ }^{10-13,30}$ Ethanol ablation and laser ablation have been demonstrated as effective and safe alternatives to traditional therapy for the treatment of AFTNs. ${ }^{31-34}$ In addition, RFA has been accepted worldwide as a minimally invasive treatment of benign thyroid nodules including non-functioning nodules and AFTN. Like LA, RFA has proven to be a safe and effective option because of the precision in inducing a welldefined area of necrosis. ${ }^{17,35}$

In our study, the efficacy and safety of RF ablation for treating AFTN were demonstrated by the ability to restore the euthyroidism stage and VRR from our long-term study in 17 patients that were performed by only radiologist with 5 years of experience. At 1 month, 3 months, 6 months, and 24 months after RFA procedure, both of clinical expression (symptom score and cosmetic score), US evaluations (vascularity grade, largest diameter, nodule volume, and VRR), thyroid scintigraphy, and thyroid function test (TSH, FT4, T3) significantly improved. With efficacy in reducing nodule volume, VRR steadily increased in every follow-up period from $42.77 \%$ at one month, $63.13 \%$ at 3 months, $78.3 \%$ at 6 months, and $95.65 \%$ at 24 months post-ablation, respectively. This is in line with the previous findings, where it has been demonstrated that RFA can increase VRR from $33 \%$ to $54 \%$ after one month post-ablation and from $51 \%$ to $75 \%$ after six months. ${ }^{16,17,19-21,36}$ However, our study showed somewhat superior results compared with other studies that showed 79-84\% of VRR after two years of followup. ${ }^{18,36}$ In addition, our study showed all 17 patients (100\%) were restored euthyroidism state which normalized serum TSH and thyroid scintigraphy after 24 months post-ablation without taking ATDs. Also, a significant improvement of mean T3 and FT4 was observed at the last follow-up. Our study exhibited a greater achievement in the percentage of patients with thyroid function normalization than previous studies with $79-86 \%$ after 2 years after the procedure. ${ }^{18,36}$ Some studies reported that a single RFA session normalized thyroid function in $33 \%$ at 3 months post-ablation, $43 \%$ at 6 months, and $40-50 \%$ at 12 months. ${ }^{20}$ Different VRR and rate of thyroid function normalization can be attributed to the difference in the number of sessions performed, the difference in techniques and devices. There are two types of techniques and devices. The first is a fixed-needle technique and a multi-tined expandable electrode. The second is the moving shot technique and a straight type of internally cooled electrode. ${ }^{16-18}$

In our study, patients complained about slight transient pain and a heat sensation during the RFA procedure and no major complications occurred. This is consistent with other previous studies. ${ }^{17,21}$ It is demonstrated that RFA is very safe for the treatment of AFTN with experienced radiologists.

Baek et al reported that the only factor affecting the treatment response was the tumor vascularity. ${ }^{17}$ In our study, the last TSH level was significantly correlated with the age of patients. In addition, the VRR at 24 months after the procedure was significantly correlated with the age of patients and initial serum TSH concentration. Other factors had no significant correlation with serum TSH and VRR.

Besides RFA, LA and EA have also been introduced as minimally invasive treatments for AFTN. In the review of literature, RFA revealed similar or slightly superior results compared with those of LA (81.7\% versus $44-81.9 \%)$, with the mean number of treatment sessions appears to be similar (1-2.2 in RF ablation versus $1-2.7$ in LA). ${ }^{21,31,32,37,38}$ EA has shown good results in normalization of the thyroid function (35.3-91.1\%) for AFTN; however, the mean number of treatment sessions is much higher. In addition, the mean volume reductions of EA seem to be inferior to those of RF ablation (43.1-66\% versus 52.1-81.7\%). ${ }^{16,17,31,33,34,39-42}$ With our results of VRR and rate of normalization of the thyroid function, RFA completely confirmed better results than LA and EA

The strength of our study is the long-term duration of the follow-up period in 24 months. Thus, this study contributes more insights into efficacy and its related factor of RFA in treating AFTN. However, our study has several limitations. Firstly, a prospective study of a single medical center with relatively small sample size is the major limitation. Secondly, some variables including IAR were not collected. Finally, our study was not designed for comparison between RFA and other therapy.

In conclusion, the results of RFA demonstrated as an effective option in the improvement of thyroid function and clinical issues in long-term follow-up for AFTN treatment without major complications. The last TSH level was significantly correlated with the age of patients and the VRR at 24 months after the procedure was significantly correlated with the age of patients and initial serum TSH concentration.

\section{Abbreviations}

ACR-TIRADS, American College Of Radiology - Thyroid Imaging Reporting and Data Systems; AFTN, Autonomously 
functioning thyroid nodule; CI, Confidence interval; EA, Ethanol ablation; FNA, Fine Needle Aspiration; FT4, Free Thyroxine; IAR, Initial ablation ratio; LA, Laser ablation; RFA, Radiofrequency ablation; RI, Radioiodine; SD, Standard deviation; T3, Triiodothyronine; TSH, Thyrotropin; VRR, Volume Reduction Rate; US, ultrasound.

\section{Data Sharing Statement}

Availability of data and materials supporting our findings will be shared upon request.

\section{Ethics Approval and Consent to Participate}

Written informed consent form was given to patients. Patients provided informed consent for the case details and any accompanying images to be published.

\section{Acknowledgments}

The authors would like to thank the patients who agreed to participate in this study and Tat Thanh Medical Equipment Company Limited for financial support.

\section{Author Contributions}

All authors contributed to data analysis, drafting or revising the article, have agreed on the journal to which the article was submitted, gave final approval of the version to be published, and agree to be accountable for all aspects of the work.

\section{Disclosure}

The authors report no conflicts of interest in this work.

\section{References}

1. Hegedüs L. Clinical practice. The thyroid nodule. $N$ Engl J Med. 2004;351(17):1764-1771. doi:10.1056/NEJMcp031436

2. Burch HB, Shakir F, Fitzsimmons TR, et al. Diagnosis and management of the autonomously functioning thyroid nodule: the Walter Reed Army Medical Center experience, 1975-1996. Thyroid. 1998;8(10):871-880. doi:10.1089/thy.1998.8.871

3. Mazzeo S, Toni MG, De Gaudio C, et al. Percutaneous injection of ethanol to treat autonomous thyroid nodules. AJR Am J Roentgenol. 1993;161(4):871-876. doi:10.2214/ajr.161.4.8372778

4. Castellana M, Virili C, Paone G, et al. Ultrasound systems for risk stratification of thyroid nodules prompt inappropriate biopsy in autonomously functioning thyroid nodules. Clin Endocrinol (Oxf). 2020;93 (1):67-75. doi:10.1111/cen.14204

5. Miccoli P, Minuto MN, Ugolini C, et al. Minimally invasive video-assisted thyroidectomy for benign thyroid disease: an evidence-based review. World J Surg. 2008;32(7):1333-1340. doi:10.1007/s00268-008-9479-y
6. Kim J-H, Baek JH, Lim HK, et al. 2017 thyroid radiofrequency ablation guideline: Korean Society of Thyroid Radiology. Korean J Radiol. 2018;19(4):632-655. doi:10.3348/kjr.2018.19.4.632

7. Bahn RS, Burch HB, Cooper DS, et al. Hyperthyroidism and other causes of thyrotoxicosis: management guidelines of the American Thyroid Association and American Association of Clinical Endocrinologists. Thyroid. 2011;21(6):593-646. doi:10.1089/ thy.2010.0417

8. Singer PA, Cooper DS, Levy EG, et al. Treatment guidelines for patients with hyperthyroidism and hypothyroidism. JAMA. 1995;273 (10):808-812. doi:10.1001/jama.1995.03520340064038

9. Cooper DS. Antithyroid drugs. $N$ Engl J Med. 1984;311 (21):1353-1362. doi:10.1056/NEJM198411223112106

10. Eyre-Brook I, Talbot C. The treatment of autonomous functioning thyroid nodules. $J$ Br Surg. 1982;69(10):577-579. doi:10.1002/ bjs. 1800691006

11. Gorman CA, Robertson JS. Radiation dose in the selection of 131I or surgical treatment for toxic thyroid adenoma. Ann Intern Med. 1978;89(1):85-90. doi:10.7326/0003-4819-89-1-85

12. Franklyn JA. The management of hyperthyroidism. $N$ Engl J Med. 1994;330(24):1731-1738. doi:10.1056/NEJM199406163302407

13. Vidal-Trecan GM, Stahl JE, Eckman MH. Radioiodine or surgery for toxic thyroid adenoma: dissecting an important decision. A cost-effectiveness analysis. Thyroid. 2004;14(11):933-945. doi:10.1089/thy.2004.14.933

14. Cesareo R, Palermo A, Pasqualini V, et al. Efficacy and safety of a single radiofrequency ablation of solid benign non-functioning thyroid nodules. Arch Endocrinol Metabol. 2017;61(2):173-179. doi:10.1590/2359-3997000000246

15. Che Y, Jin S, Shi C, et al. Treatment of benign thyroid nodules: comparison of surgery with radiofrequency ablation. $\mathrm{Am}$ $J$ Neuroradiol. 2015;36(7):1321-1325. doi:10.3174/ajnr.A4276

16. Deandrea M, Limone P, Basso E, et al. US-guided percutaneous radiofrequency thermal ablation for the treatment of solid benign hyperfunctioning or compressive thyroid nodules. Ultrasound Med Biol. 2008;34(5):784-791. doi:10.1016/j.ultrasmedbio.2007.10.018

17. Baek JH, Moon W-J, Kim YS, et al. Radiofrequency ablation for the treatment of autonomously functioning thyroid nodules. World J Surg. 2009;33(9):1971-1977.

18. Spiezia S, Garberoglio R, Milone F, et al. Thyroid nodules and related symptoms are stably controlled two years after radiofrequency thermal ablation. Thyroid. 2009;19(3):219-225. doi:10.1089/ thy. 2008.0202

19. Faggiano A, Ramundo V, Assanti AP, et al. Thyroid nodules treated with percutaneous radiofrequency thermal ablation: a comparative study. JClin Endocrinol Metab. 2012;97(12):4439-4445. doi:10.1210/jc.2012-2251

20. Bernardi S, Stacul F, Michelli A, et al. 12-month efficacy of a single radiofrequency ablation on autonomously functioning thyroid nodules. Endocrine. 2017;57(3):402-408. doi:10.1007/s12020-016-1174-4

21. Sung JY, Baek JH, Jung SL, et al. Radiofrequency ablation for autonomously functioning thyroid nodules: a multicenter study. Thyroid. 2015;25(1):112-117.

22. Dobnig H, Amrein K. Monopolar radiofrequency ablation of thyroid nodules: a prospective Austrian single-center study. Thyroid. 2018;28 (4):472-480. doi:10.1089/thy.2017.0547

23. Vuong NL, Dinh LQ, Bang HT, et al. Radiofrequency ablation for benign thyroid nodules: 1-year follow-up in 184 patients. World J Surg. 2019;43(10):2447-2453. doi:10.1007/s00268-019-05044-5

24. Nguyen VB, Nguyen TX, Nguyen VVH, et al. Efficacy and safety of single-session radiofrequency ablation in treating Benign thyroid nodules: a short-term prospective cohort study. Int $J$ Endocrinol. 2021;2021:1-7. doi:10.1155/2021/7556393 
25. Ha EJ, Baek JH, Che Y, et al. Radiofrequency ablation of benign thyroid nodules: recommendations from the Asian Conference on Tumor Ablation Task Force. Ultrasonography. 2021;40(1):75. doi:10.14366/usg.20112

26. Baek JH, Kim YS, Lee D, et al. Benign predominantly solid thyroid nodules: prospective study of efficacy of sonographically guided radiofrequency ablation versus control condition. Am J Roentgenol. 2010;194(4):1137-1142. doi:10.2214/AJR.09.3372

27. Park HS, Baek JH, Choi YJ, et al. Innovative techniques for image-guided ablation of benign thyroid nodules: combined ethanol and radiofrequency ablation. Korean J Radiol. 2017;18(3):461-469. doi:10.3348/kjr.2017.18.3.461

28. Goldberg S, Grassi CJ, Cardella JF, et al. International Working Group on Image-Guided Tumour Ablation. Image-guided tumour ablation: standardization of terminology and reporting criteria. Radiology. 2005;235:728-739. doi:10.1148/radiol.2353042205

29. Ezzat S, Sarti DA, Cain DR, Braunstein GD. Thyroid incidentalomas: prevalence by palpation and ultrasonography. Arch Intern Med. 1994;154(16):1838-1840.

doi:10.1001/ archinte.1994.00420160075010

30. Conzo G, Docimo G, Ruggiero R, et al. Surgical treatment of papillary thyroid carcinoma without lymph nodal involvement. G Chir. 2012;33(10):339-342.

31. Spiezia S, Vitale G, Di Somma C, et al. Ultrasound-guided laser thermal ablation in the treatment of autonomous hyperfunctioning thyroid nodules and compressive nontoxic nodular goiter. Thyroid. 2003;13(10):941-947. doi:10.1089/105072503322511346

32. Pacella CM, Bizzarri G, Guglielmi R, et al. Thyroid tissue: USguided percutaneous interstitial laser ablation - a feasibility study. Radiology. 2000;217(3):673-677. doi:10.1148/radiology.217.3. r00dc09673

33. Lippi F, Ferrari CA, Manetti LU, et al. Treatment of solitary autonomous thyroid nodules by percutaneous ethanol injection: results of an Italian multicenter study. The Multicenter Study Group. J Clin Endocrinol Metab. 1996;81(9):3261-3264.
34. Livraghi T, Paracchi A, Ferrari C, et al. Treatment of autonomous thyroid nodules with percutaneous ethanol injection: preliminary results. Work in progress. Radiology. 1990;175(3):827-829. doi:10.1148/radiology.175.3.2188302

35. Pacella CM, Bizzarri G, Spiezia S, et al. Thyroid tissue: US-guided percutaneous laser thermal ablation. Radiology. 2004;232 (1):272-280. doi:10.1148/radiol.2321021368

36. Cesareo R, Naciu AM, Iozzino M, et al. Nodule size as predictive factor of efficacy of radiofrequency ablation in treating autonomously functioning thyroid nodules. Int $J$ Hyperthermia. 2018;34 (5):617-623. doi:10.1080/02656736.2018.1430868

37. Gambelunghe G, Fatone C, Ranchelli A, et al. A randomized controlled trial to evaluate the efficacy of ultrasound-guided laser photocoagulation for treatment of benign thyroid nodules. $J$ Endocrinol Invest. 2006;29(9):RC23-RC26. doi:10.1007/BF03347368

38. Barbaro D, Orsini P, Lapi P, et al. Percutaneous laser ablation in the treatment of toxic and pretoxic nodular goiter. Endocrine Pract. 2007;13(1):30-36. doi:10.4158/EP.13.1.30

39. Tarantino L, Francica G, Sordelli I, et al. Percutaneous ethanol injection of hyperfunctioning thyroid nodules: long-term follow-up in 125 patients. Am J Roentgenol. 2008;190(3):800-808. doi:10.2214/AJR.07.2668

40. Brkljacic B, Sucic M, Bozikov V, et al. Treatment of autonomous and toxic thyroid adenomas by percutaneous ultrasound-guided ethanol injection. Acta radiologica. 2001;42(5):477-481. doi:10.1080/ 028418501127347205

41. Guglielmi R, Pacella CM, Bianchini A, et al. Percutaneous ethanol injection treatment in benign thyroid lesions: role and efficacy. Thyroid. 2004;14(2):125-131. doi:10.1089/105072504322880364

42. Monzani F, Caraccio N, Goletti O, et al. Five-year follow-up of percutaneous ethanol injection for the treatment of hyperfunctioning thyroid nodules: a study of 117 patients. Clin Endocrinol (Oxf). 1997;46(1):9-15. doi:10.1046/j.1365-2265.1997.d01-1752.x
Therapeutics and Clinical Risk Management

\section{Publish your work in this journal}

Therapeutics and Clinical Risk Management is an international, peerreviewed journal of clinical therapeutics and risk management, focusing on concise rapid reporting of clinical studies in all therapeutic areas, outcomes, safety, and programs for the effective, safe, and sustained use of medicines. This journal is indexed on PubMed Central, CAS,

\section{Dovepress}

EMBase, Scopus and the Elsevier Bibliographic databases. The manuscript management system is completely online and includes a very quick and fair peer-review system, which is all easy to use. Visit http://www.dovepress.com/testimonials.php to read real quotes from published authors. 